\title{
Circumareolar Versus Circumvertical Mastopexy with Augmentation
}

\author{
Basim A. Awan, MD, FRCS(C) \\ Department of Surgery, Division of Plastic Surgery, Faculty of Medicine \\ King Abdulaziz University, Jeddah, Saudi Arabia
}

\section{Correspondence \\ Dr. Basim A. Awan \\ P.O. Box 80215 \\ Jeddah 21589, Saudi Arabia \\ e.M: drbasimawan@gmail.com \\ Submission: 16 July 2017 \\ Accepted: 27 July 2017}

\section{Citation}

Awan BA. Circumareolar versus circumvertical mastopexy with augmentation. JKAU Med Sci 2017; 24 (4): 21-30. DOI: 10.4197/Med. 24.4.4

\begin{abstract}
The main aim of augmentation mastopexy is to obtain harmonic relation between breast volumes, shape and scar. There are several variations of the modified breast lift, including circumareolar and circumvertical techniques, each of which has its own unique characteristics and approaches. The aim of this retrospective study was to evaluate and compare the uses of circumareolar ( $n=55,27.20 \%)$ versus circumvertical ( $n=147,72.80 \%$ ) augmentation-mastopexy in 202 women over a 10 years period. Results showed that 28 patients $(50.90 \%)$ with circumareolar augmentation-mastopexy need revised surgery due to undesired breast shape $(n=24,43.60 \%)$, stretched areola $(n=17,30.90 \%)$ and bad scar $(n=9,16.40 \%)$; while 32 patients (22.40\%) with circumvertical augmentation-mastopexy need revised surgery due to secondary ptosis $(n=29,19.70 \%)$, large areola $(n=3$, $2.00 \%$ ) and unpleasant vertical scar $(n=13,8.80 \%)$. The present study concluded that circumareolar augmentation-mastopexy procedure showed less satisfactory results with undesirable breast and areola shape and bad scars, while circumvertical augmentation-mastopexy gives better results for the areola and breast shape with less potential revision.
\end{abstract}

\section{Keywords}

Augmentation-mastopexy; Breast lift; Breast ptosis;

Circumareolar mastopexy; Circumvertical mastopexy

\section{Introduction}

$M$ astopexy is a cosmetic surgical procedure that involves breasts rising to a more desirable height, as well as modifying and/or contouring breast tissue ${ }^{[1]}$. Indications for an augmentation and mastopexy include a nipple-areola complex (NAC) that is below the inframammary fold (IMF), Regnault's Grade II to III ptosis, excess breast skin relative to breast parenchyma, and breast ptosis that is more than $2 \mathrm{~cm}$ below IMF. The goals of this procedure are to elevate the position of the NAC, enhance breast volume, and tighten the skin envelope to improve breast contour and position ${ }^{[2]}$. Weight loss in a short period of time, pregnancy, breast feeding, and gravity lead to increasingly pendulous ptotic breasts with loss of firmness, downward pointing nipples and projection. Many women wish to lift the breast to restore a more youthful appearance. The challenge remains restoring a more youthful breast and maintaining nipple sensation while minimizing complications ${ }^{[3]}$.

Augmentation-mastopexy has been considered a risky procedure ${ }^{[4]}$. Many investigators advise staging the surgery for patients with a higher risk of complications ${ }^{[4-9]}$. However, two operations are 
inconvenient and more costly for patients. The procedure that is performed in a single stage appeared attractive to both patient and surgeon ${ }^{[10]}$. Meanwhile, it was reported that the safest plan for correction of breast asymmetries may be to perform mastopexy first followed by breast augmentation at a second stage ${ }^{[11,12]}$.

Mastopexy done traditionally uses skin excision maneuvers; however, since the mid-1990s, there was an emphasis on parenchymal tissue internal shaping. The classic skin excision patterns are crescent, periareolar, circumvertical, and inverted-T. Internal shaping is done using supportive material (implant) or parenchymal pillars $^{[2]}$. The type of mastopexy done depends on the degree of breast ptosis. A crescent mastopexy can be considered when the degree of NAC elevation does not exceed $1 \mathrm{~cm}$. A periareolar or circumareolar mastopexy can be considered when the distance of NAC elevation ranges from 1 to $2 \mathrm{~cm}$ that is classified as a Regnault I or II. After the skin excision, the outer perimeter of dermis is scored, and the subcutaneous plane is undermined circumferentially to allow for adequate redraping of skin envelope over parenchyma. A circumvertical mastopexy will lift the base of the breast as well as reposition NAC and is usually used for Regnault II or III breast ptosis. The inverted-T technique is useful for the moderate to severely ptotic breast classified as Regnault III. The horizontal incision will reduce the distance from NAC to IMF, while vertical incision will reduce the base diameter. The L-shaped mastopexy eliminates the medial portion of inverted-T incision and is done for Grade I to II breast ptosis ${ }^{[2]}$. Implants can be placed in a variety of tissue planes through mastopexy incisions, including a subpectoral, subglandular, or subfascial placement ${ }^{[13]}$.

The present retrospective study aimed to evaluate the uses of circumareolar vs. circumvertical augmentation-mastopexy procedures in patients with Grade II and III ptosis and compare their outcomes.

\section{Materials and Methods}

Two hundred and two patients who had undergone augmentation-mastopexy between April 2006 and March 2016 were recruited in this retrospective study; of them 147 (72.80\%) had circumvertical augmentationmastopexy and 55 (27.20\%) had circumareolar augmentation-mastopexy. Evaluation preoperatively started systematically that includes a thorough history and physical examination with particular attention to oncologic history and previous breast surgeries, pregnancy, breast feeding history, medications, and hormone replacement therapy; history of weight fluctuations, bleeding, or clotting problems; and indications of mastopexy. A physical evaluation includes height and weight measurement, assessment of breast size and surface area, skin elasticity, quality of breast parenchyma, areolar diameter, and asymmetry as well as the relation between nipple, breast gland and IMF to determine the degree of breast ptosis. Implant data was also collected including insertion technique, type and style, brand and volume. Mastopexy technique as well as follow up period and postoperative complications were also collected. All patients made a baseline mammogram before surgery. Preoperative and postoperative photography were collected.

Preoperative ptosis grade was recorded using Regnault scale, Grade I, mild (nipple position lying at or above IMF level); Grade II, moderate (nipple position below the IMF but still on anterior portion of breast); Grade III, severe (nipple position below IMF at the most inferior portion of the breast) and glandular ptosis or pseudoptosis (nipple position above IMF but the breast tissue is below the fold).

\section{Methods}

All procedures were performed at a state licensed ambulatory surgery center.

\section{Circumareolar Augmentation- Mastopexy}

All patients who underwent circumareolar augmentedmastopexy had Grade II ptosis. Preoperative planning of circumareolar mastopexy begins by defining the ventral midline, breast meridians and IMFs while the patient is in an upright position with arms down the side. The chest midline and the IMF are marked with an indelible marker. The upper point of the new location of the NAC was marked, the lower point of the new NAC was marked $7 \mathrm{~cm}$ from the IMF. Medial and lateral borders marked as needed to remove extra skin. The outer circle of the donut was completed by joining the four points. The areola circle was drawn with a 5 $\mathrm{cm}$ diameter. The operation starts by subglandular insertion of the desired implant through infra-areolar incision through the gland then the mastopexy outer circle is adjusted as needed. The donut skin between outer and inner circle then de-epithelialized. A round block suture $2 / 0$ proline was used to close the circumareolar wound ${ }^{[14]}$. 


\section{Circumvertical Augmentation - Mastopexy}

All patients who underwent circumvertical augmentedmastopexy had Grade II or III ptosis. In circumvertical augmentation mastopexy the new location of the NAC marked preoperatively in a standing position and designed as omega shape open circle with 14 $\mathrm{cm}$ circumference when closed it would give $4.5 \mathrm{~cm}$ diameter circle. Two lines dropped downward from the two ends of the omega with the expected excess skin excised in between. Before performing mastopexy, the desired size breast implant was inserted through the infra-areola incision and was placed subglandular or subpectoral with partial release of pectoralis muscle. The NAC reduced in diameter to $5 \mathrm{~cm}$ and elevated to its new position based on superior pedicle. After that excess skin and tissue were excised vertically inferior to NAC. The length of NAC-IMF distance adjusted to 7-8 $\mathrm{cm}$, any extra length transferred to horizontal line at the IMF level.

All patients wore medical or sports bras for about 6 weeks and were told they could resume exercising by one month after surgery. Patients were instructed not to perform heavy lifting for 4-6 weeks. Patients advised to sleep in an elevated position for one week and avoid sleeping prone for 4- 6 weeks. Follow up data and information were obtained for 4 months to 6 years.

\section{Results}

Twenty-eight (50.90\%) patients out of 55 who underwent circumareolar mastopexy came for revision while $33(22.40 \%)$ out of 147 who underwent circumvertical mastopexy came for revision. Indications for revision in circumareolar augmentationmastopexy cases includes undesired shape ( $n=24$, $43.60 \%$ ) as boxy shaped breast, ptosis, asymmetry of the breast; areolar disorders ( $n=17,30.90 \%)$ such as stretch, distortion and flat nipple; and bad scar ( $\mathrm{n}=$ 9, 16.40\%) such as flattening, stretching, wrinkling and hypertrophy (Table 1 and Fig. 1, 2). Indications for revision in circumvertical augmentation-mastopexy cases $(n=33,22.40 \%)$ involved mainly secondary ptosis $(n=29,19.70 \%)$, then wide vertical scar $(n=13,8.80 \%)$ and areolar disorders $(n=3,2.00 \%)$ (Table 1 and Fig. 3 ).

\section{Discussion}

Augmentation mastopexy is regarded with trepidation by many plastic surgeons. Many researchers reported that this procedure multiplies complications ${ }^{[15,16]}$. Augmentation mastopexy have several aims; the implant fills the skin envelope, meanwhile mastopexy tightens the skin envelope ${ }^{[8,9,15-17]}$. Many surgeons'advise staging when doing augmentation mastopexy ${ }^{[6,8,9,16]}$. In cosmetic surgery, the patient's opinion regarding the quality of the result is the most important indicator of surgical success ${ }^{[1,18]}$. Surgeons differ in how they define complications ${ }^{[1]}$; some surgeons do not consider cosmetic issues such as asymmetry, persistent ptosis, or scar deformities as complications ${ }^{[19]}$, while others do not recognize implant size change as a complication ${ }^{[8]}$.

Augmentation mammaplasty is frequently used to fill out the soft tissue envelope of the breast. This is most successful with minimal skin laxity or when there is no need for significant nipple movement. The addition of a periareolar mastopexy can reduce the skin envelope; however, its value is limited to those with no more than mild second-degree ptosis. Although this is a valuable technique, the risks involved with the operation are additive, and, accordingly, patient selection and surgical technique is important.

The final aim during augmenting and breast lifting were shape balance, minimizing the scar and decreasing the recurrence of ptosis. To reduce the occurrence of misalignment requires continuous reevaluation of the nipple implant relationship to the breast. For this reason, we put the implant and restoration of the anatomy of the breast first, then we reassess the relationship between the breast, the nipple and the implant, before skin envelope excision and mastopexy closure are completed. The same procedure was documented by others ${ }^{[12]}$.

Table 1. Revised surgery and aesthetic in the problems of 202 patients who underwent augmentation-mastopexy.

\begin{tabular}{|l|c|c|c|}
\hline \multicolumn{1}{|c|}{ Complications } & $\begin{array}{c}\text { Total } \\
(\mathbf{n}=\mathbf{2 0 2}, \mathbf{1 0 0 \% )}\end{array}$ & $\begin{array}{c}\text { Circumareolar Augmentation Mastopexy } \\
(\mathbf{n}=\mathbf{5 5 , 2 7 . 2 0 \% )}\end{array}$ & $\begin{array}{c}\text { Circumvertical Augmentation Mastopexy } \\
(\mathbf{n}=\mathbf{1 4 7}, \mathbf{7 2 . 8 0} \%)\end{array}$ \\
\hline Revision Surgery & $61(30.20 \%)$ & $28(50.90 \%)$ & $33(22.40 \%)$ \\
\hline Undesired Shape & $53(26.20 \%)$ & $24(43.60 \%)$ & $29(19.70 \%)$ \\
\hline Areola Disorders & $20(9.90 \%)$ & $17(30.90 \%)$ & $3(2.00 \%)$ \\
\hline Bad Scars & $22(10.90 \%)$ & $9(16.40 \%)$ & $13(8.80 \%)$ \\
\hline
\end{tabular}



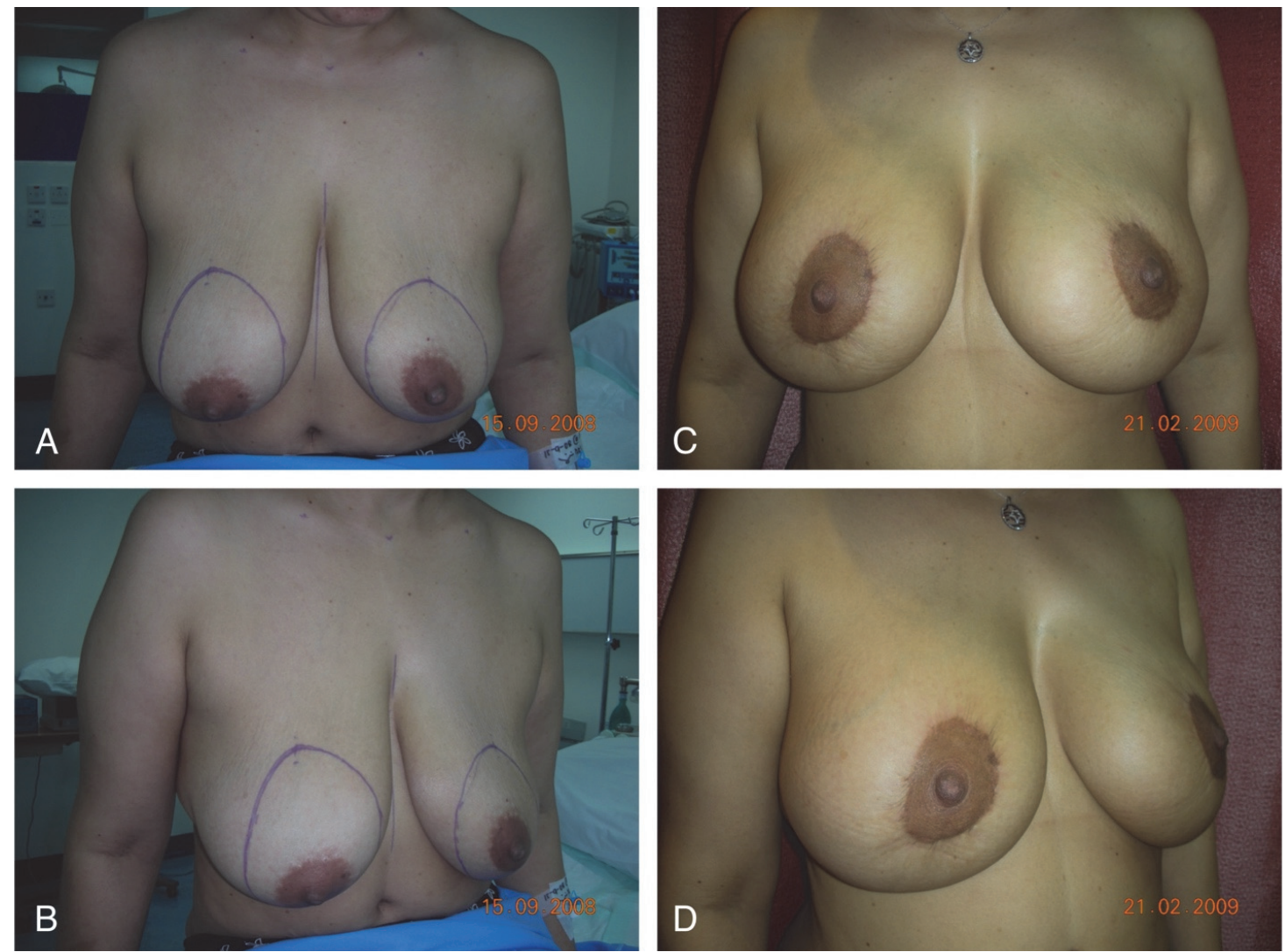

Figure 1. 38-year-old female post multiple pregnancies and breast feeding. (A, B): Grade Il ptosis pre-operative (C, D): 5 months post circumareolar augmentation-mastopexy (275 cc implants, subglandular) shows boxy shape breast, stretched and distorted areola.
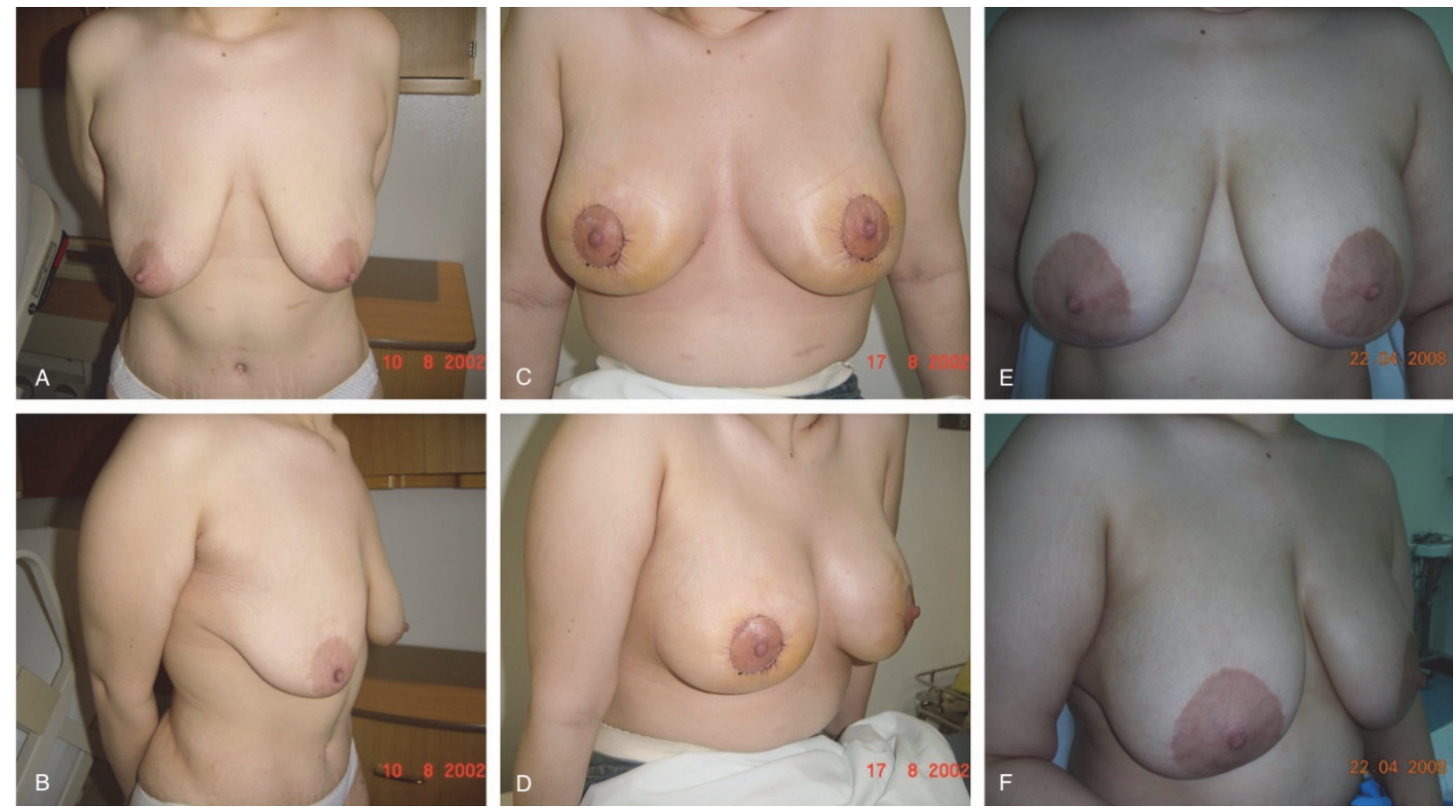

Figure 2. 28-year-old female post massive weight loss. (A, B): Grade II ptosis pre op. (C, D): 1week post circumareolar augmentationmastopexy (350 cc implants, subglandular) notice areola size and purse string round block. (E, F): 6 years post op areola stretched, nipple flattened and secondary ptosis. 

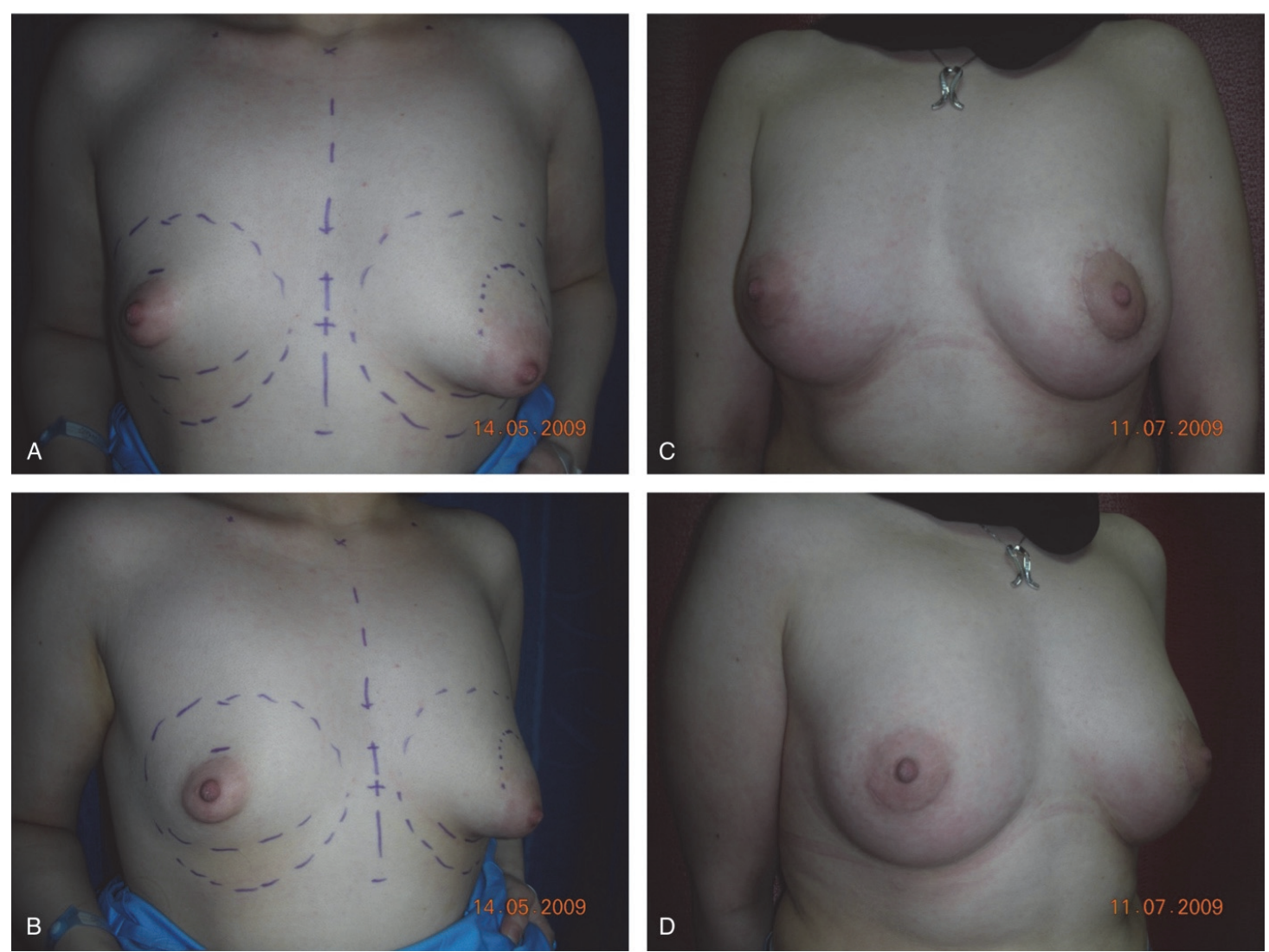

Figure 3. 22-year-old female with bilateral asymmetric tuberous breast (A, B): pre-operative (C, D): 2 months post-operative Rt. side only breast implant 260 cc, Lt. cicumareolar augmentation-mastopexy (200 cc implant).

In this study, 55 patients with Grade II ptosis had circumareolar augmentation-mastopexy. Keeping the incision periareolar aimed to hide the operation scar as per patient's wishes. A permanent purse-string suture maintains scar tension and spread and prevents areolar enlargement that occurs with other procedures. Placement only along the outside circumference is less effective than the "wagon-wheel" method that also incorporates the areola and reduces wound tension ${ }^{[20]}$. Periareolar (circumareolar) mastopexy can reduce areolar diameter and simultaneously raise nipple position modestly $(<2 \mathrm{~cm})$ by using an eccentric shaped excision pattern that includes intra-areolar skin. It can also correct nipple position asymmetry when used unilaterally. Although outside incision diameters up to $12 \mathrm{~cm}$ have been advocated, those not exceeding $7 \mathrm{~cm}$ will reliably avoid problems with pleating, central flattening, wide scars, areolar spreading, and the loss of skin texture inherent in this technique. An alternative recommendation is that the ratio of outside diameter to areolar diameter should not exceed $2: 1^{[21,22]}$. In this study, revised surgery after circumareolar augmentation-mastopexy was done in $28(50.90 \%)$ out of 55 patients. The indications for revision surgery were undesired shape such as boxy shape breast, ptosis, asymmetry of the breast in 24 (43.60\%) cases; areolar disorders such as stretch, distortion and flattened nipple in 17 (30.90\%) cases and bad scar such as stretched, wrinkled and hypertrophy in 9 (16.40\%) cases. Patients who come for augmentation mastopexy usually ask for fewer scars and want to limit the scar around the areola. Limiting the excision of the excess skin around the areola and when the outer circle reaches more than double the circumference of the inner circle of the donut mastopexy, the tension of closure leads to stretching back of the areola and distorted circle because when the tight breast brassiere loosens up after a few weeks to a few months it does so in variable degrees and directions. The too many wrinkles of the outer circle will never disappear completely leading to visible scarring. Tightening the skin brassiere in the center of the breast mound leads to loss of this mound and less projection. In this respect, it had been reported that a disadvantage of 
this procedure is that the potential of mastopexy is limited. If used injudiciously, breast flattening, areolar distortion, and poor scars may result ${ }^{[23]}$.

Women with significant ptosis, large areolas, and little skin between areola and inframammary crease as in tuberous breast are poor candidates for standard vertical mastopexy. The decrease of lower pole skin led to short vertical limbs that diverge at a narrow angle and minimizes elevation of the nipple. In addition, the vertical limbs may not diverge wide enough to skirt outside the areolar margin. Patients with this anatomy (Fig. 3) are candidates for a circumareolar mastopexy ${ }^{[13]}$. In circumvertical mastopexy with augmentation the newly sized areola will be transferred to an exact size opening that make it rest peacefully with no tension around it. Excising the excess skin inferiorly and tightening the breast brassiere from below leads to more breast projection and nice shape and mound (Fig.
4). In this study 147 patients underwent augmentationcircumvertical mastopexy, of them 33 (22.40\%) patients required revision surgery. The indications of revision surgeries were secondary ptosis ( $n=29,19.70 \%$ ), then bad scar ( $n=13,8.80 \%)$ and areolar disorders ( $n=3,2.00 \%$ ). Boxy breast shape rarely results from vertical mastopexy. One cause is a skin envelope not tight enough due to inadequate displacement of the breast to each side during the skin-marking process. This can be corrected later by plicating the vertical incision until the shape is improved. Another cause is too much glandular tissue volume left lateral to pillars at their base. This can be avoided during dissection by increasing glandular excision adjacent to skin just lateral to pillars on each side ${ }^{[24]}$. Lejour ${ }^{[25]}$ in her experience of 152 circumvertical mastopexy patients reported that complications included four cases with seromas, six cases with hematomas and one case with infection.
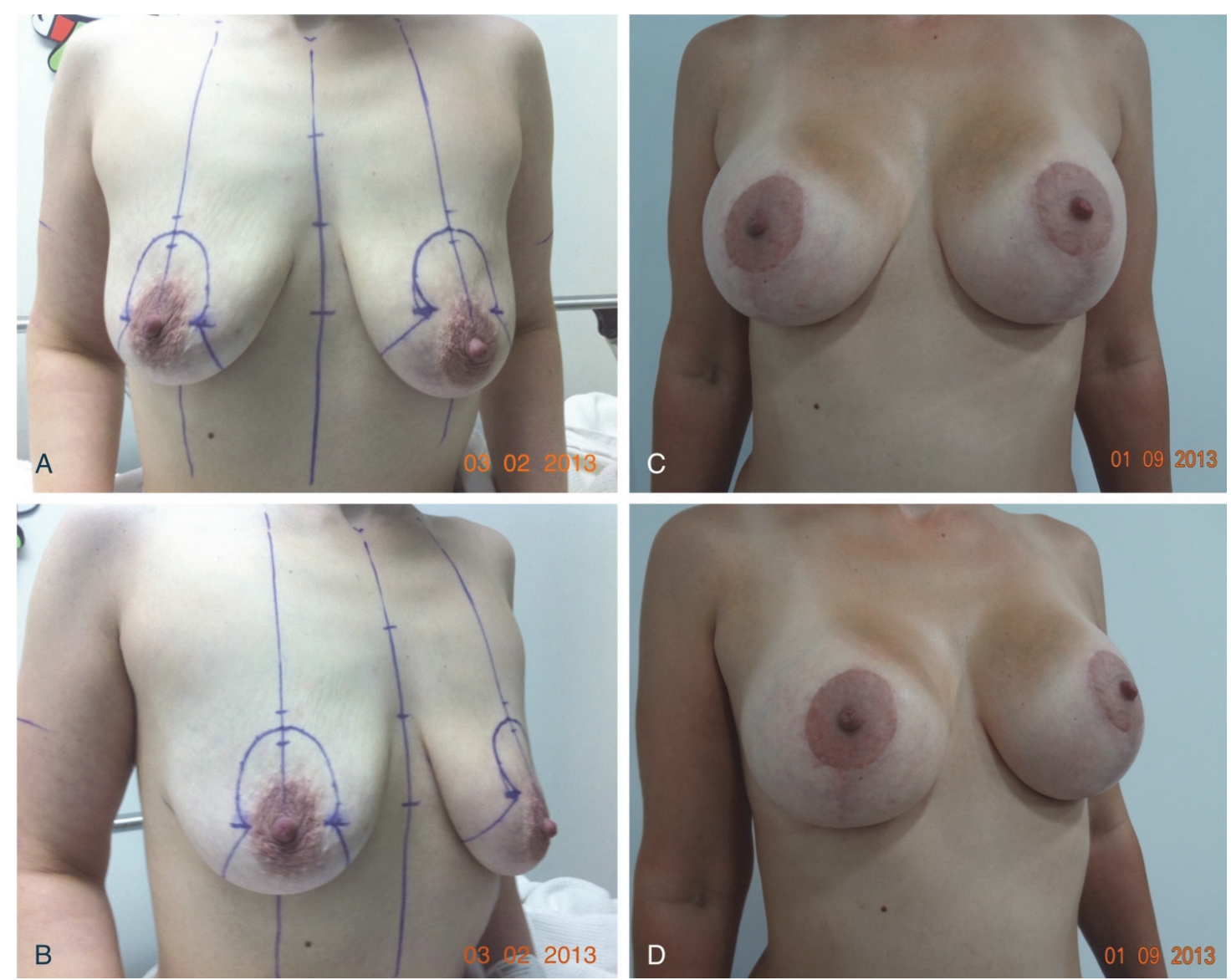

Figure 4. 32-year-old female mother after two pregnancies and breast feeding. (A, B): Grade Il ptosis pre-operative (C, D): seven months post circumvertical augmentation-mastopexy (300cc implants, subpectoral) shows nice round shape breast with good projection and nice rested nipple areolar complex. 
Comparing results of circumvertical mastopexy and circumareolar mastopexy obtained by this study showed less satisfactory results were obtained with circumareolar mastopexy with augmentation because of bad scar, stretched areola or undesired breast shape (Fig. 5,6$)$ and more frequency of revision surgery ${ }^{[26]}$.
Others reported that complications following augmentation-mastopexy, and reductions were hematoma and infection being most common ${ }^{[11,27]}$. Freidman ${ }^{[28]}$ has outlined several preventative measures when considering simultaneous augmentation and mastopexy. These include subpectoral device
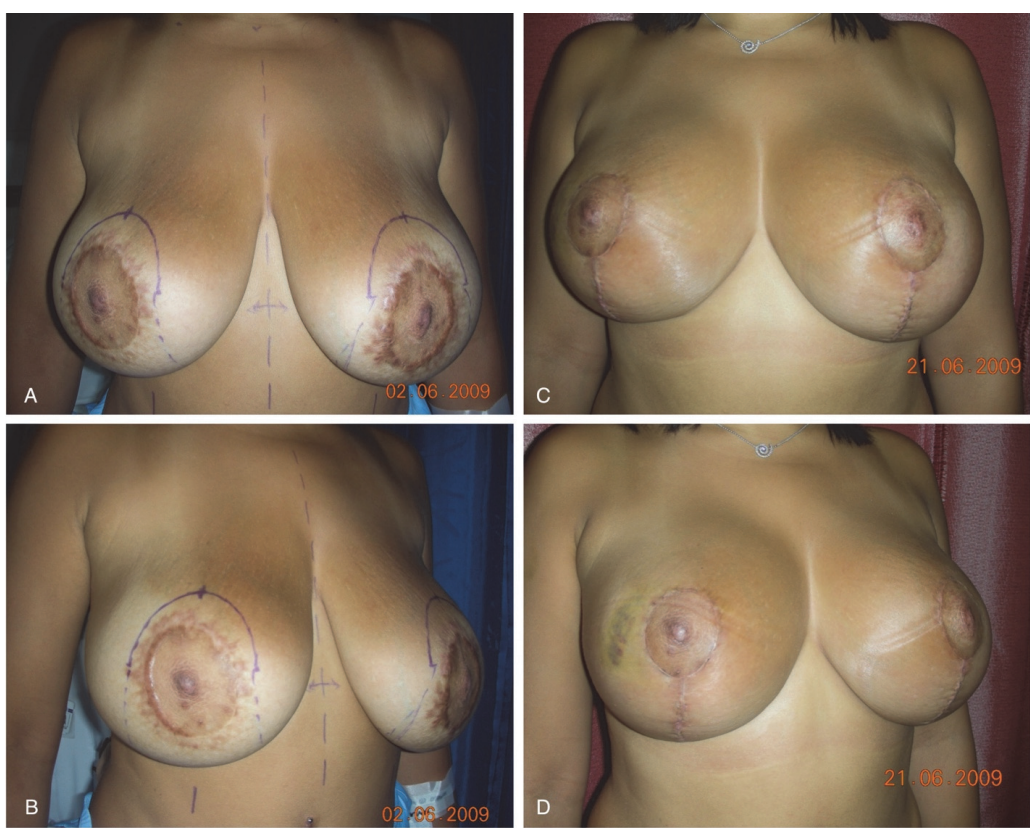

Figure 5. 26-year-old female, four years post bilateral circumareolar augmentation-mastopexy. (A, B): Areolas stretched with bad hypertrophic scar. (C, D): three weeks post revision with circumvertical augmentation-mastopexy (310 g implants).
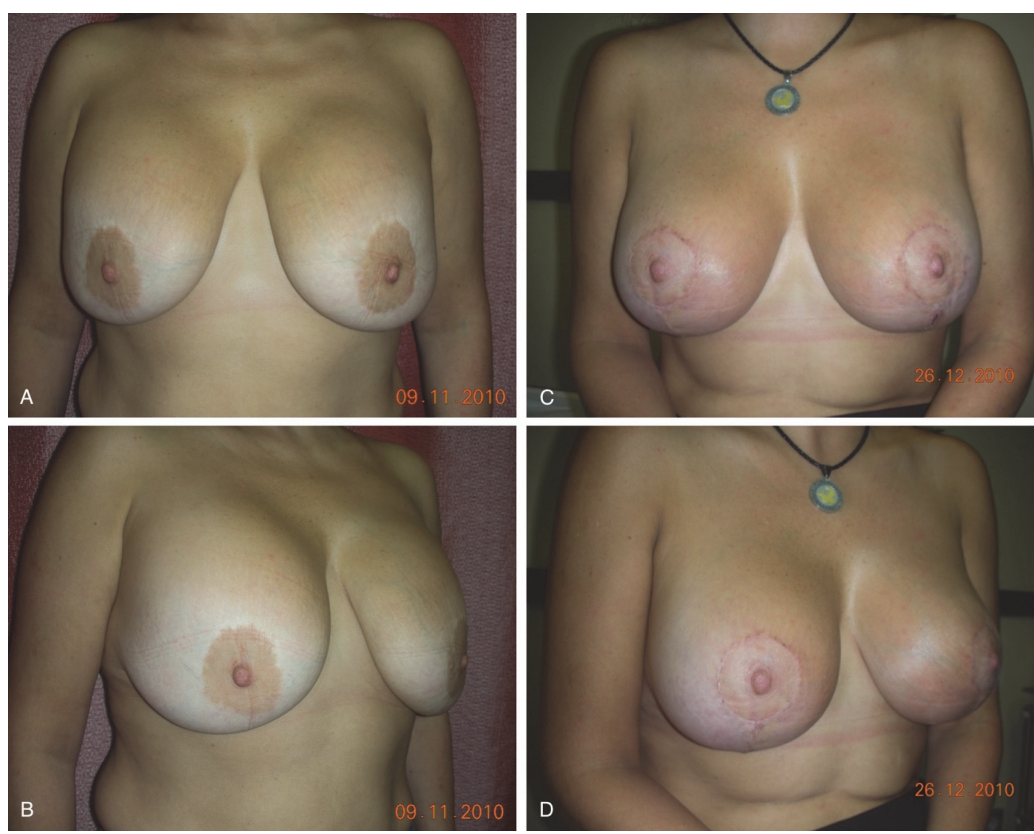

Figure 6. 35-year-old female two years post circumareolar augmentation-mastopexy done by other surgeon (A, B) notice flattened breast with secondary ptosis. (C, D): Six weeks post revision with circumvertical augmentation-mastopexy (265 g implants, subpectoral). 
placement, augmentation before mastopexy, tailortacking the skin envelope, avoidance of inverted-T incisions, and parenchymal resection as needed. One study comparing circumareolar, vertical, and inverted-T techniques found suture "spitting" as the most common problem with all three, with excessive scarring next. Complication rates were $41.5 \%$ for circumareolar, 9.7\% for vertical, and $14 \%$ for inverted-T techniques ${ }^{[29]}$. Seroma, capsular contracture, and implant malposition are among the added risks when simultaneous augmentation is performed. Complications in a study of 321 patients undergoing augmentation mastopexy included saline implant deflation (3.7\%), capsular contracture $(1.9 \%)$, poor scarring $(2.5 \%)$, areolar asymmetry $(2.2 \%)$, and recurrent ptosis $(2.2 \%)^{[30]}$. Common indications for mastopexy revision include recurrent ptosis and scar problems. The highest revision surgery rate was reported with circumareolar techniques, the highest incidence of bottoming out was reported with inverted-T techniques, and the highest incidence of asymmetry was reported with vertical techniques method ${ }^{[29]}$. Another study corroborated the highest incidence of revision occurring with circumareolar methods (27\%) versus all other methods $(14.6 \%)^{[31]}$. When combined with augmentation, indications for revision include recurrent ptosis, capsular contracture, implant malposition, implant deflation, size change, poor scars, nipple malposition, or some combination thereof ${ }^{4,300}$.

\section{Conclusion}

Augmentation-mastopexy can be a safe and gratifying procedure for both the patient and surgeon when performed with thoughtful planning and careful execution. The present study indicated that circumareaolar augmentation-mastopexy procedure showed a less satisfactory result with scarring due to excessive tension closure around the areola leading to NAC stretching and distortion and breast shape flattening with loss of mound and more frequency of revision surgery while the circumvertical augmentationmastopexy gives a nicely rested areola with less visible scarring and nicely shaped breast with good projection and mound. Circumareolar mastopexy can be limited to certain cases that need elevation of NAC to $1 \mathrm{~cm}$ or to cases with short NAC-IMF distance and narrow base as in patients with Tuberous breast.

\section{Conflict of Interest}

The author has no conflict of interest.

\section{Disclosure}

The author did not receive any commercial or financial support for this study. The author has no financial interest in any of the products, devices, or drugs mentioned in this article.

\section{Ethical Approval}

Obtained.

\section{References}

[1] Swanson E. Prospective photographic measurement study of 196 cases of breast augmentation, mastopexy, augmentation/ mastopexy, and breast reduction. Plast Reconstr Surg 2013; 131(5): 802e-819e.

[2] Nahabedian MY. Breast deformities and mastopexy. Plast Reconstr Surg 2011; 127(4): 91e-102e.

[3] Elliot LF. Circumareolar mastopexy with augmentation. Clin Plast Surg 2002; 29(3): 337-347.

[4] Spear SL. Augmentation/mastopexy: "surgeon beware". Plast Reconstr Surg 2006; 118(7 Suppl): 133S-135S.

[5] Spear SL, Pelletiere CV, Menon N. One-stage augmentation combined with mastopexy: aesthetic results and patient satisfaction. Aesthetic Plast Surg 2004; 28(5): 259-267.

[6] Don Parsa F, Brickman M, Parsa AA. Augmentation/ mastopexy. Plast Reconstr Surg 2005; 115(5): 1428-1429.

[7] Nahai F, Fisher J, Maxwell PG, Mills DC 2nd. Augmentation mastopexy: to stage or not. Aesthet Surg J 2007; 27(3): 297-305.

[8] Calobrace MB, Herdt DR, Cothron KJ. Simultaneous augmentation/mastopexy: a retrospective 5-year review of 332 consecutive cases. Plast Reconstr Surg 2013; 131(1): $145-156$.

[9] Lee MR, Unger JG, Adams WP Jr. The tissue-based triad: A process approach to augmentation mastopexy. Plast Reconstr Surg 2014; 134(2): 215-225.

[10] Persoff MM. Vertical mastopexy with expansion augmentation. Aesthet Plast Surg 2003; 27(1): 13-19.

[11] Gorney M, Maxwell PG, Spear SL. Augmentation mastopexy. Aesthet Surg J 2005; 25(3): 275-284.

[12] Gruber R, Denkler K, Hvistendahl Y. Extended crescent mastopexy with augmentation. Aesthetic Plast Surg 2006; 30(3): 269-276.

[13] Hidalgo DA, Spector JA. Mastopexy. Plast Reconstr Surg 2013; 132(4): 642e-656e.

[14] Maxwell GP. Breast asymmetry. Aesthetic Surg J 2001; 121(6): 552-562.

[15] Spear SL, Dayan JH, Clemens MW. Augmentation mastopexy. Clin Plast Surg 2009; 36(1): 105-115. 
[16] Beale EW, Ramanadham S, Harrison B, Rasko Y, Armijo $\mathrm{B}$, Rohrich RJ. Achieving predictability in augmentation mastopexy. Plast Reconstr Surg 2014; 133(3): 284e-292e.

[17] Spring MA, Hartmann EC, Stevens WG. Strategies and challenges in simultaneous augmentation mastopexy. Clin Plast Surg 2015; 42(4): 505-518.

[18] Ching S, Thoma A, McCabe RE, Antony MM. Measuring outcomes in aesthetic surgery: a comprehensive review of the literature. Plast Reconstr Surg 2003; 111(1): 469-480.

[19] Thoma A, Ignacy TA, Duku EK, Patterson RS, Cin AD, Levis CM, Goldsmith CH. Randomized controlled trial comparing health-related quality of life in patients undergoing vertical scar versus inverted T-shaped reduction mammaplasty. Plast Reconstr Surg 2013; 132(1): 48e-60e.

[20] Hammond DC, Alfonso D, Khuthaila DK. Mastopexy using the short scar periareolar inferior pedicle reduction technique. Plast Reconstr Surg 2008; 121(5): 1533-1539.

[21] Spear S L, Kassan M, Little JW. Guidelines in concentric mastopexy. Plast Reconstr Surg 1990; 85(6): 961-966.

[22] Spear SL, Giese SY, Ducic I. Concentric mastopexy revisited. Plast Reconstr Surg 2001; 107(5): 1294-1299.

[23] Davison SP, Spear SL. Simultaneous breast augmentation with periareolar mastopexy. Semin Plast Surg 2004; 18(3): 189-201.

[24] Hidalgo DA. Vertical mammoplasty. Plast Reconstr Surg 2005; 115(4): 1179-1197.

[25] Lejour M. Vertical mammaplasty and liposuction of the breast. Plast Reconstr Surg 1994; 94(1): 100-114.

[26] Baran CN, Peker F, Ortak T, Sensöz O, Baran NK. Unsatisfactory results of periareolarmastopexy with or without augmentation and reduction mammaplasty: enlarged areola flattened nipple. Aesthetic Plast Surg 2001; 25(4): 286-289.

[27] Gupta V, Yeslev M, Winocour J, Bamba R, Rodriguez-Feo C, Grotting JC, Higdon KK. Aesthetic breast surgery and concomitant procedures: incidence and risk factors for major complications in 73,608 cases. Aesthet Surg J 2017; 37(5): 515-527.

[28] Freidman RM. Augmentation/mastopexy: "surgeon beware". Plast Reconstr Surg 2004; 113(7): 2230-2231.

[29] Rohrich RJ, Gosman AA, Brown SA, Reisch J. Mastopexy preferences: a survey of board-certified plastic surgeons. Plast Reconstr Surg 2006; 118(7): 1631-1638.

[30] Stevens WG, Freeman ME, Stoker DA, Quardt SM, Cohen R, Hirsch EM. One-stage mastopexy with breast augmentation: a review of 321 patients. Plast Reconstr Surg 2007; 120(6): 1674-1679. 


\title{
مقارنه بين شد الثدي بإستئصال دائري حول الهالة وشند الثاي بإستئصال عمودي
}

\author{
باسم عبد الله أوان \\ قسم الجر/حة \\ كلبة الطب الطرالي \\ جامعة الملك عبد العزبيز \\ جده ـ المدلكة العربية السعودية
}

الهستخلص. الهذف الرئيسي من شد وتكبير الثدي هو الحصول على علاقة متناسقة بين حجم الثذي وشكله و الندبات الناتجة.

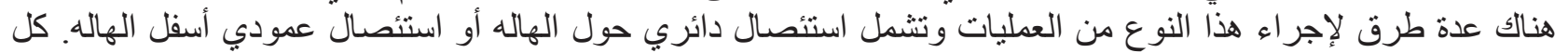

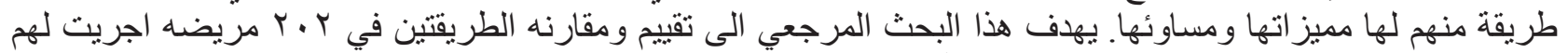

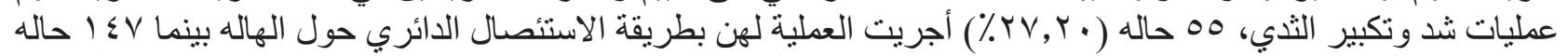

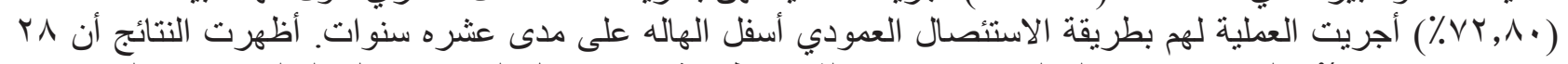

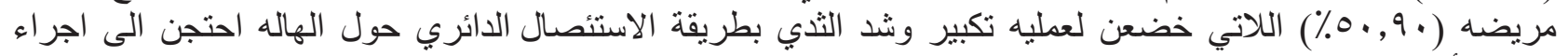

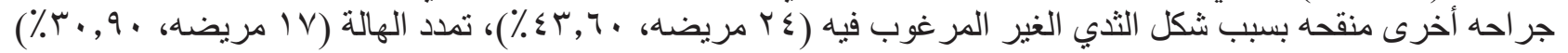

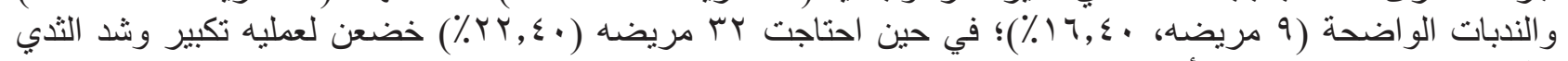

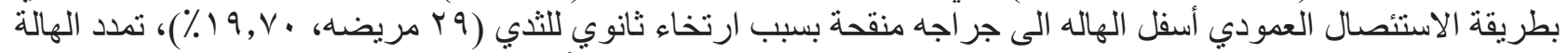

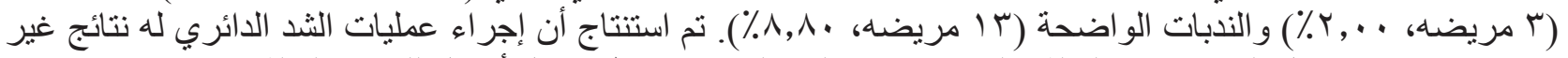
مرضيه من حيث شكل الثذي وتمدد الهالة والندبات، بينما الثند العمودي يعطي شكل أفضل للثندي و الهالة. 